\title{
Hombres sonorenses: un estudio de género de tres generaciones Guillermo Núñez Noriega (2013)
}

\author{
José Eduardo Calvario Parra*
}

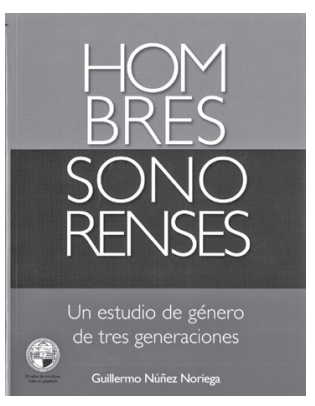

En Sonora hay poca producción académica sobre las relaciones de género, y en especial sobre las que se dan entre varones desde la perspectiva de las ciencias sociales y de género. La obra que hoy se comenta viene a contribuir y a llenar esta laguna. Una cualidad del libro Hombres sonorenses: un estudio de género de tres generaciones, de Guillermo Núñez Noriega (2013), Universidad de Sonora y Pearson (Educación de México), aparte de las propiamente académicas, es el estilo ligero, ameno y sencillo en que se redactó. Leerlo es un buen pretexto para conocer a los varones de una región serrana de Sonora.

El autor y editores mantienen un balance respecto al estilo y al formato del contenido. Se evita publicar una obra llena de citas, pies de páginas y referencias teóricas que socaven la fluidez de la lectura, pero a la vez, que sea lo suficientemente sólida para sostener en términos analíticos lo que se expone.

La obra en referencia es producto de una investigación socioantropológica en la región conocida como los pueblos del río Sonora (Ures, Baviácora, Aconchi, San Felipe de

\footnotetext{
* Licenciado en Sociología por la Universidad de Sonora, Maestro en Ciencias Sociales con especialidad en salud por el Colegio de Sonora, Doctor en Ciencias Sociales por el Colegio de México. Profesorinvestigador Cátedras Conacyt en El Colegio Sonora, Profesor de asignatura en la Universidad de Sonora. joseduardo_calv@yahoo. com.mx
}

Jesús, Huépac, Banámichi, Arizpe y Bacoachi), cuyos objetivos son, a decir del autor:

1. Conocer desde una perspectiva del género, las concepciones, valores, actitudes y prácticas sexuales y reproductivas en tres grupos de varones según criterio de edad (adultos mayores, 45-55).

2. Conocer los cambios de un grupo hacia otro.

3. Conocer la dirección de dichos cambios con relación al grupo más joven. La metodología empleada es de corte cualitativa. De esta manera, se utilizan recursos metodológicos como entrevistas a profundidad, observación participante, entrevistas informales.

El trabajo se ubica dentro de lo que se ha llamado estudios de las masculinidades, o como prefiere llamarle el autor, estudio de género de los hombres. Guillermo Núñez va enriqueciendo sus datos recopilados con reflexiones analíticas, usando categorías analíticas provenientes del pensamiento feminista, antecedentes directos de los estudios de las masculinidades, y de algunas alusiones conceptuales a autores como Michel Foucault y Pierre Bourdieu.

El concepto de reproducción es crucial en el análisis de Núñez Noriega. Para él, el uso tradicional se ha supeditado al ámbito biológico, y en realidad este concepto transciende las áreas que comúnmente se le asocian. Los significados, por lo menos para los entrevistados relacionados con la reproducción, implican no solo la paternidad, la fecundidad y la gestación, sino además el papel en la división del trabajo, el vínculo emocional y sexual con la pareja, como padre-esposo-compañero, sus privilegios, los placeres y satisfacciones. 


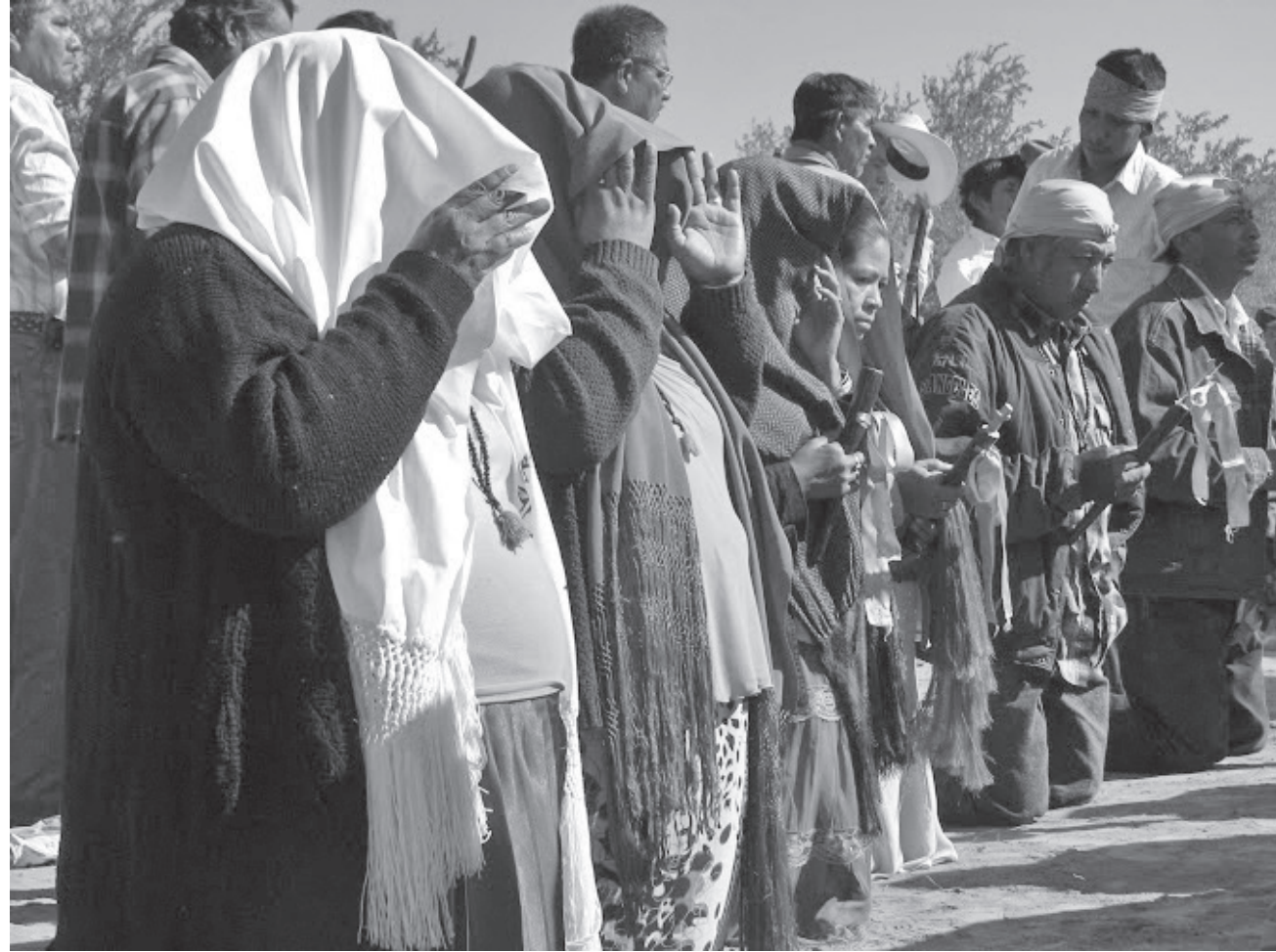

Rosario por los guerreros. Ceremonia en honor del regreso de los restos de los guerreros yaquis masacrados por el ejército en 1902 en la sierra de Mazatán. Los 107 cuerpos fueron llevados a los Estados Unidos y allá permanecieron, en el Museo de Historia Natural de Nueva York, hasta el 2007 (A. Valenzuela).

La importancia del trabajo es central en los tres grupos, pero cobra mayor relevancia para el primero. En este grupo, los varones se sintieron hombres cuando empezaron a trabajar. Además, el trabajo estuvo vinculado con lo que los entrevistados refieren con mantener y atender. El mantener les corresponde a ellos; mientras que el atender, a sus esposas. También el trabajo es fuente de prestigio, orgullo, porque permite que se les considere como "hombre trabajador" y se convierte en un buen prospecto para el mercado matrimonial. El trabajo y la hombría son parte, según el autor, de la idea del gobierno de uno mismo, de la independencia económica (p. 25).

La socialización estuvo vinculada a los espacios

La organización del contenido del libro consiste en presentar en sus tres capítulos, información y análisis de cada generación; así mismo, se brinda un contexto sociodemográfico e histórico de cada grupo de varones.

Lo interesante de la obra de Núñez Noriega es la forma en que va hilando los hallazgos con una interpretación analítica que tiene dos bases: la información cualitativa y los datos del contexto. Los componentes de las identidades de género que conforman los horizontes valorativos y cognitivos de sus informantes le sugieren interesantes hipótesis y niveles de análisis.

Para explorar los significados sobre los valores, concepciones y prácticas sobre el aspecto reproductivo y sexual de la vida de los entrevistados, la relación con el entorno social le da al esfuerzo analítico de Núñez un valor socioantropológico insoslayable. Las categorías sociales, marcadores de distinción (como las refiere el autor), por ejemplo, vaquetón, vago, lépero, huevon, están presentes en la experiencia de los tres grupos generacionales, pero se re significarán a la luz de los cambios sociales y las propias relaciones de género.

En el primer capítulo recorre varios de los hilosideológicos y las prácticas que sustentan el interés de la investigación. Los varones nacidos entre 1919-1930, los adultos mayores, corresponden al primer grupo de varones, los cuales tenían de 73 a 83 años de edad al momento de las entrevistas. Este grupo de varones fueron socializados en un mundo completamente rural, de economía de autosuficiencia. En esa época existía muy poca o nula comunicación entre los pueblos y las incipientes ciudades como la capital del estado. tradicionales como la iglesia, la propia familia, y el lugar de trabajo. Existió una férrea disciplina para algunos de los entrevistados sobre todo por parte de sus papás. Las distancias físicas y supervisión en el noviazgo, el nulo conocimiento sobre el cuerpo femenino hasta antes de su primera relación sexual y la asociación de las prácticas sexuales con fines estrictamente reproductivos son una de las diferencias con los otros dos grupos generacionales.

Los valores como la fidelidad conyugal y la virginidad estuvieron en relación directa con la idea que las prácticas sexuales tienen que ser con fines reproductivos y no por placer. Por otro lado, las actividades de la crianza, la participación en el parto, y sobre todo la paternidad, se supeditaron sobre el eje: mantener-dirigir/enseñar.

La rigidez de los padres en cuanto a la disciplina, la mínima apertura para conversar (economía del habla de la que alude el autor) y la ausencia de muestra de afecto, son prácticas que la literatura especializada ha llamado modelo tradicional masculino. El texto de Núñez nos muestra que dicho modelo no es monolítico y que no se presenta de la misma manera en tiempo y espacio. Se establecen fisuras, resignificaciones, pero no son homogéneas ni iguales para todas las regiones del país.

En el segundo capítulo se aborda el caso del segundo grupo generacional, aquellos nacidos entre 1947-1956. Tenían entre 45 y 55 años de edad al momento de la investigación. Les tocó vivir la cristalización de las primeras políticas de modernización en la sierra de Sonora, y junto a ello, los cambios demográficos, económicos y culturales se expresaron a lo largo y ancho del país. Escuelas, centros de salud, campañas gubernamentales a favor de la planificación 
familiar, crecimiento poblacional, vacunación masiva, son solo algunos eventos que se expresaban en distintas latitudes y ámbitos de la vida diaria de los entrevistados.

Una característica diferenciadora de estos varones frente a la generación anterior fue que en el proceso de socialización, la importancia de la versatilidad laboral adquirió singular importancia; pero además, con la posibilidad, por lo menos en el imaginario social, de que también podían realizar trabajo doméstico. Todo ello, constituyó una fuente de orgullo para ellos (p. 78). No existió un momento específico en que se "sintieron hombres". Lejos de ubicar un momento, este grupo de varones, a decir de Núñez, vivieron un cúmulo de experiencias que les fue proveyendo un marco de sentido sobre la hombría. El autor los llama "efectos de saturación". Al parecer, en este grupo pesa más la idea de un hombre con múltiples experiencias de saber y aventura. A diferencia del primer grupo (p. 75) implica una influencia en sus significados y prácticas sobre la sexualidad y el ámbito reproductivo.

La relación de la sexualidad y la masculinidad esconde su complejidad en el momento que, para Núñez, el contexto situacional y el saber sexual se interconectan para el vínculo entre la identidad masculina y el aprendizaje sexual. El proceso de transición entre dejar de ser niño y ser hombre, el inicio de la vagancia como referente de masculinización en su horizonte de sentido, se transforman en el hombre vaquetón, en una necesidad de ser vaquetón, en tanto referente.

Otra diferencia con el anterior grupo es relajamiento de la vigilancia estrecha en el noviazgo, pero que a final de cuentas sigue persistiendo. El primer grupo estuvo contenido por una serie de silencios y economía del habla. En el tema de sexualidad, el segundo grupo contestó que llevaron prácticas de autoerotismo, situación distinta al primer grupo, pero rechazaron la pornografía (p. 107) y prácticas sexuales no convencionales. Anteponen, dice Núñez, un discurso sanitarista y con adjetivos; expresaron que esas prácticas sexuales "son maniacadas".

El casarse les significó responsabilidad, un esquema de vida, pero frente a ello se gestan elementos desprestigiadores. Un caso interesante de marcador de distinción y de minusvalor de la hombría, es el de decirle "cotorro" a aquel varón que no se casó, o está mayor y no se ha casado. El uso en el discurso de dicha categoría puede tener implicaciones de orden social-económico, pues al no tener una familia, ni una descendencia biológica, los vínculos con la comunidad pueden ser más endebles. Vale la pena una referencia al trabajo de campo, en la que narra que un comprador de unos terrenos, exclama indignado "pinche bola de cotorros", para referirse a un grupo de ejidatarios que se niega a vender su propiedad para la instalación de una maquiladora (p. 120). A nuestro autor le genera curiosidad la asociación e indaga al respecto. Entiende que el sentido que le da el potencial comprador es el débil lazo que establecen los "cotorros" con el bienestar de la comunidad, pues no tienen hijos y por tanto, no se preocupan por el progreso.

Por otro lado, existe una construcción de un discurso más igualitario con sus esposas tanto de ayuda en el ámbito doméstico como el rechazo a situaciones machistas (irresponsabilidad, autoritarismo, control del cuerpo de las mujeres [p. 117]). Los varones del primer grupo dan por sentado que las mujeres no deben trabajar mientras ellos puedan mantener a la familia; en tanto, los del segundo grupo, permiten que sus esposas trabajen; de esta manera, se erige un discurso de corresponsabilidad. En el tema de la paternidad, estos varones se distancian con la paternidad de sus padres; se entiende que es una relación social, pero también intersubjetiva que no se deriva simplemente de ser hombre, y surgen nuevos obligaciones y tareas.

En el tercer capítulo se abordan los varones de la tercera generación, con una edad entre los 20 y 25 años de edad al momento de la entrevista. El contexto en el que vivieron estos varones tiene que ver con la proliferación de los medios masivos de comunicación, principalmente radio y televisión, y con una mayor oferta educativa (preparatorias). Se instauraron las primeras maquiladoras de la región y

\section{Savìa}




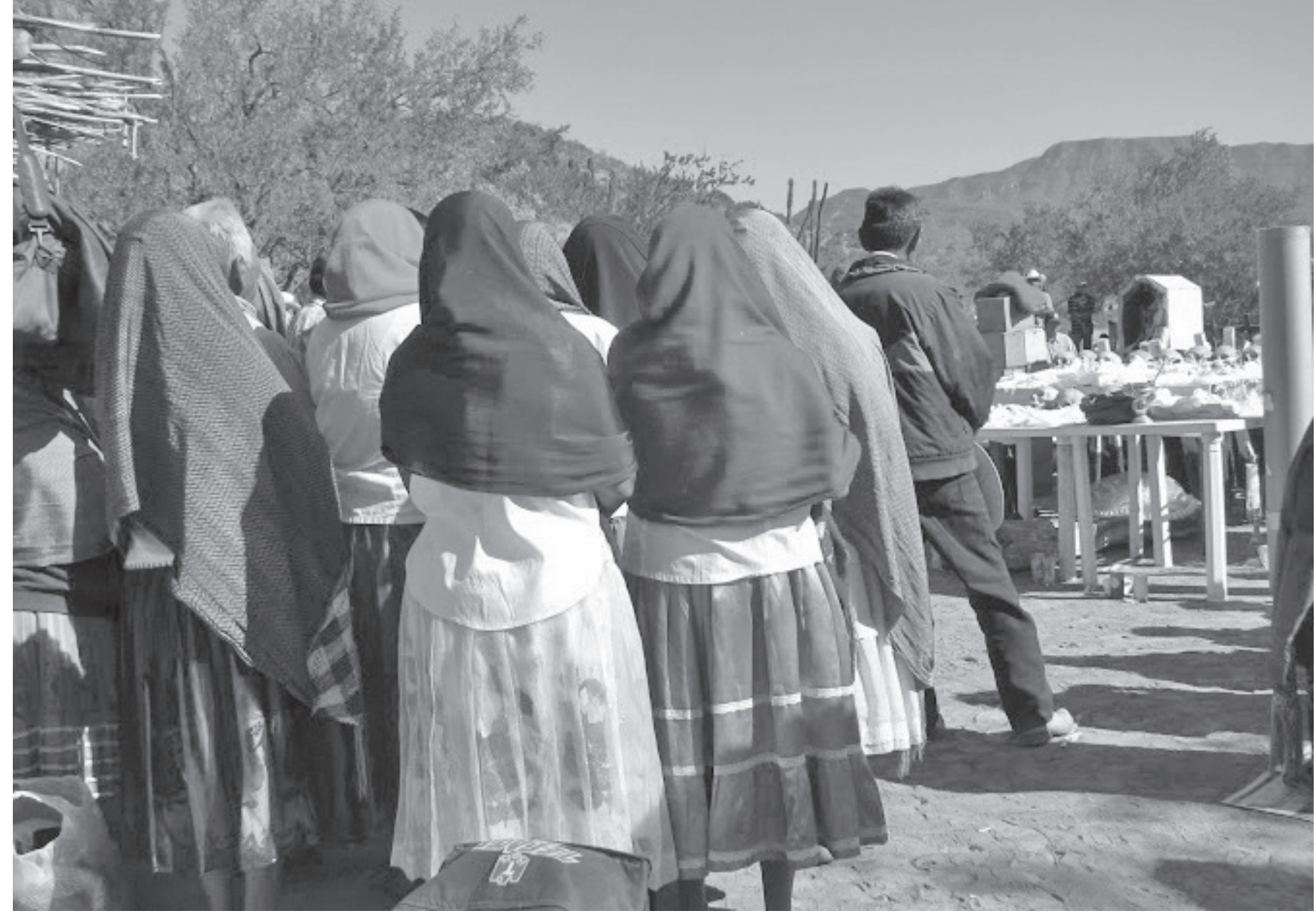

Reverencia por los guerreros. Profundo respeto por los restos de los guerreros yaquis (A. Valenzuela).

existieron las primeras presidentas municipales de Sonora, tres de ellas de los pueblos de esta región.

El proceso de sentirse hombre, en este grupo de varones, nos relata el autor, si bien tiene puntos en común con las dos anteriores generaciones; se distingue porque tiene la apertura para contar cualquier tema y son capaces de tomar una posición crítica respecto a las ideologías de género tradicionales.

Algunas de las orientaciones de la acción social de estos varones son la idea de rudeza, de maldad, la práctica de recibir o dar "carrilla", y participar en pleitos, así como el no tener miedo (no ser culón). En los intersticios de estas configuraciones de género se expresan interpretaciones alternativas a las formas de la masculinidad dominante. Así, a pesar que en el imaginario, el ideal viril se asocia con el poder económico (dinero), la fuerza-astucia física ("buenos para los chingazos"), el ser valiente y el reconocimiento de la necesidad de andar por otros senderos, a veces se expresa en situaciones emocionales (p. 151).

Respecto a la información y aprendizaje sexual, este grupo se diferencia con los otros dos en que tuvieron acceso a fuentes no solamente escolares y de pláticas gubernamentales (como por ejemplo, el DIF -Sistema Nacional para el Desarrollo Integral de la Familia-), sino a medios masivos como la televisión, los videos y revistas pornográficas. La primera relación sexual estuvo mediada por el lazo afectivo y placentero. La elección de la novia ya no se centró en la división entre mujeres buenas y mujeres malas. El reconocimiento a la masturbación con grupo de pares en la adolescencia marca cambios con las anteriores generaciones, al decir del autor.

Así también, y aunque siguen operando las ideologías de género tradicionales, este grupo de jóvenes resignificó algunos valores como la participación en el embarazo y parto. Son más proclives a tener una opinión favorable a la vasectomía, no así para el caso del aborto. La autoridad masculina cobró menos importancia, al menos en el discurso. La paternidad siguió teniendo importancia para la identidad masculina, en especial el acercamiento afectivo y asertivo con los/as hijos/as.

Con la inserción de la industria de la maquiladora se registraron cambios en la división social del trabajo. Ello a su vez, trajo consigo nuevas configuraciones en los espacios del trabajo con la incorporación femenina en la fuerza laboral.

En suma, el libro es un referente obligado para aproximarnos a explicaciones de los procesos de transformación en las relaciones de género en Sonora. Abre pistas sobre las cuales es posible transitar para entender las resignificaciones de lo que es ser un hombre en Sonora. Representa una importante contribución en México a los estudios de género centrado en los varones. Nos muestra que los traslapes, las reconfiguraciones, las contradicciones en el seno de los modelos de género, son posibles y obedecen a la confluencia de los factores estructurales y las subjetividades de los agentes. 